\title{
Thermal and hydraulic performance analysis of a heat sink with corrugated channels and nanofluids
}

\author{
Benyamin Naranjani ${ }^{1} \cdot$ Ehsan Roohi ${ }^{2,3} \cdot$ Amin Ebrahimi $^{4}$
}

Received: 28 November 2019 / Accepted: 2 September 2020 / Published online: 21 September 2020

(c) The Author(s) 2020

\begin{abstract}
Cooling of electronic devices is one of the critical challenges that the electronics industry is facing towards sustainable development. Aiming at lowering the surface temperature of the heat sink to limit thermally induced deformations, corrugated channels and nanofluids are employed to improve the thermal and hydraulic performances of a heat sink. Three-dimensional simulations based on the finite-volume approach are carried out to study conjugated heat transfer in the heat sink. Waterbased nanofluids containing $\mathrm{Al}_{2} \mathrm{O}_{3}$ nanoparticles with two different particle sizes ( $29 \mathrm{~nm}$ and $40 \mathrm{~nm}$ ) and volume fractions less than $4 \%$ are employed as the coolant, and their influence on the thermal and hydraulic performance of the heat sink is compared with the base fluid (i.e. water). An empirical model is utilised to approximate the effective transport properties of the nanofluids. Employing corrugated channels instead of straight channels in the heat sink results in an enhancement of $24-36 \%$ in the heat transfer performance at the cost of $20-31 \%$ increase in the required pumping power leading to an enhancement of 16-24\% in the overall performance of the heat sink. Additionally, the numerical predictions indicate that the overall performance of the proposed heat sink design with corrugated channels and water- $\mathrm{Al}_{2} \mathrm{O}_{3}$ nanofluids is $22-40 \%$ higher than that of the water-cooled heat sink with straight channels. It is demonstrated that the overall performance of the heat sink cooled with water- $\mathrm{Al}_{2} \mathrm{O}_{3}$ nanofluids increases with reducing the average nanoparticle size. Additionally, the maximum temperature rise in the heat sinks is determined for different thermal loads.
\end{abstract}

Keywords Heat sink · Thermal performance $\cdot$ Energy efficiency $\cdot$ Laminar forced convection $\cdot$ Nanofluid $\cdot$ Electronic cooling

Amin Ebrahimi

A.Ebrahimi@tudelft.nl

1 Department of Civil Engineering and Mechanics, University of Wisconsin-Milwaukee, Milwaukee, WI 53201, USA

2 Department of Mechanical Engineering, Faculty of Engineering, Ferdowsi University of Mashhad, P.O. Box 91775-1111, Mashhad, Khorasan Razavi, Iran

3 State Key Laboratory for Strength and Vibration of Mechanical Structures, International Center for Applied Mechanics (ICAM), School of Aerospace Engineering, Xi' an Jiaotong University (XJTU), Xi'an, China

4 Department of Materials Science and Engineering, Delft University of Technology, Mekelweg 2, 2628CD Delft, The Netherlands

\section{Introduction}

Devising effective cooling systems is crucial to make an advancement in electronic packaging technology and to support the sustainable development of modern devices. Progressive enhancement of the performance, reliability and miniaturisation of devices emerges thermal challenges and requires highly effective heat removal equipment [1]. Employing single-phase microchannel heat sinks (MHS) stands among the enabling solutions for high-heat-flux removal [2-4]. Various approaches and designs have been applied to enhance the thermal performance of heat sinks, among which a promising passive technique is to utilise surface features in integrated cooling systems [5]. Surface features can be employed in different forms such as pin-fin structures [6-8], vortex generators [9-11] and corrugated channels [12-15]. However, the increased pumping power required to drive coolants in cooling systems is an inherent unfavourable circumstance [5]. A better understanding of 
heat and fluid flow in heat sinks is indispensable to engineer heat exchangers to meet high-heat-flux removal targets.

Applying corrugated channels in MHSs can increase heat transfer performance and pressure loss $[16,17]$ compared with their corresponding straight channels. This is mainly due to the formation of secondary flow that enhances fluid mixing and disturbs thermal boundary layer [18]. Geometrical configuration of corrugated channels and thermophysical properties of the coolant also affect heat and fluid flow structures [19-22]. Khoshvaght-Aliabadi et al. [23] numerically studied the influence of different cross-section shapes on heat transfer performance of straight and corrugated minichannels under laminar flow regime. Their results showed that the cross-section shape of the channel can significantly affect the heat transfer performance of corrugated channels. Salami et al. [24] studied the influence of different wave shapes on turbulent heat and fluid flow in corrugated channels and reported that the sinusoidal wave shape, in comparison with triangular and trapezoidal wave shapes, can result in a higher thermal-hydraulic performance. The results reported by Sakanova et al. [20], Lin et al. [21], KhoshvaghtAliabadi et al. [25] indicate that increasing the amplitude or reducing the wavelength of corrugations intensifies the induced secondary flow that can lead to an enhancement in heat transfer performance. Khoshvaght-Aliabadi and Sahamiyan [26] studied the effect of corrugated channels on heat transfer performance of heat sinks with corrugated channels and reported that the influence of the amplitude of waves on heat transfer augmentation is larger than that of wavelength. The formation of secondary flow in corrugated channels augments the pressure drop along the channels [12, 27]. To improve the overall thermo-hydraulic performance of MHSs, both high heat-removal capability and low pressure-drop are required.

Increasing the effective thermal conductivity of conventional heat transfer liquids is a promising approach to improve the heat-removal capability of MHSs [28]. This can be done by making stable suspensions of ultra-fine solid particles and fibres with thermal conductivities higher than that of the base fluids [29, 30], which is widely known as "nanofluids" [31]. However, the augmented viscosity of nanofluids can increase pressure penalty, particularly for MHSs [10, 32-35]. It is, therefore, essential to study nanofluid flow and heat transfer characteristics in MHSs to optimise the factors that influence the thermo-hydraulic performance of cooling systems.

Thermophysical properties of nanofluids depend on nanoparticle volume fraction, material, shape, size and bulk temperature [36-38]. To predict the characteristics of heat and fluid flow at miniature scales with reasonable accuracy, taking the temperature dependence of material properties into consideration is crucial $[9,10,39]$. Experimental studies on thermal conductivity of nanofluids have demonstrated that traditional theoretical models [40-44] fail to predict the viscosity and enhanced thermal conductivity of nanofluids $[30,36]$. This is due to the neglect of the effects of nanoparticle Brownian motion, size distribution and aggregation of particles, and inter-facial thermal resistance between nanoparticles and the surrounding liquid [30, 45]. Koo and Kleinstreuer [46, 47] developed an empirical model to predict the thermal conductivity and viscosity of nanofluids that takes the nanoparticle size, volume fraction, Brownian motion and temperature dependence as well as base fluid properties into account. The accuracy and reliability of this model have been validated extensively against experimental datasets $[10,48,49]$.

In the present work, three-dimensional calculations are carried out to investigate the thermo-hydraulic performance of a miniature heat sink with corrugated channels and nanofluids. The motivation of the present work is to reduce the temperature rise of the heat sink to limit thermal deformations for high-heat-flux removal applications such as laser-mirror cooling and electronic packaging. The effect of replacing straight channels with corrugated channels in the heat sink is investigated. Moreover, water-based nanofluids containing $\mathrm{Al}_{2} \mathrm{O}_{3}$ nanoparticles with different sizes $(29 \mathrm{~nm}$ and $40 \mathrm{~nm})$ and volume fractions $(0-3 \%)$ are employed to investigate the thermo-hydraulic performance of the heat sink. The thermophysical properties of the nanofluid are approximated using a model that takes temperaturedependent material properties, nanoparticle size and volume fraction as well as the Brownian motion of particles into consideration. Temperature rise in the heat sink is reported for different thermal loadings and heat sink configurations. The performance of the heat sink with corrugated channels and nanofluids is compared with that of a water-cooled heat sink with straight channels. The mechanisms of heat transfer enhancement and the temperature distribution over the heat sink surface are also discussed.

\section{Problem description}

The heat sink considered in the present work has a diameter of $57 \mathrm{~mm}$ and consists of three layers and is schematically shown in Fig. 1. The geometrical configuration of the heat sink is inspired by that proposed by [50]; however, the influence of employing corrugated channels and straight channels on the thermal and hydraulic performance of the heat sink is investigated in the present work. The top surface of the heat sink's top layer was heated by applying a constant uniform heat flux to a circular region with a diameter of $30 \mathrm{~mm}$, as is shown in Fig. 1d, e. Different values of heat flux ranging between 35 and $350 \mathrm{~kW} \mathrm{~m}^{-2}$ were studied. The top layer of the heat sink has a thickness of $2 \mathrm{~mm}$. The coolant enters 

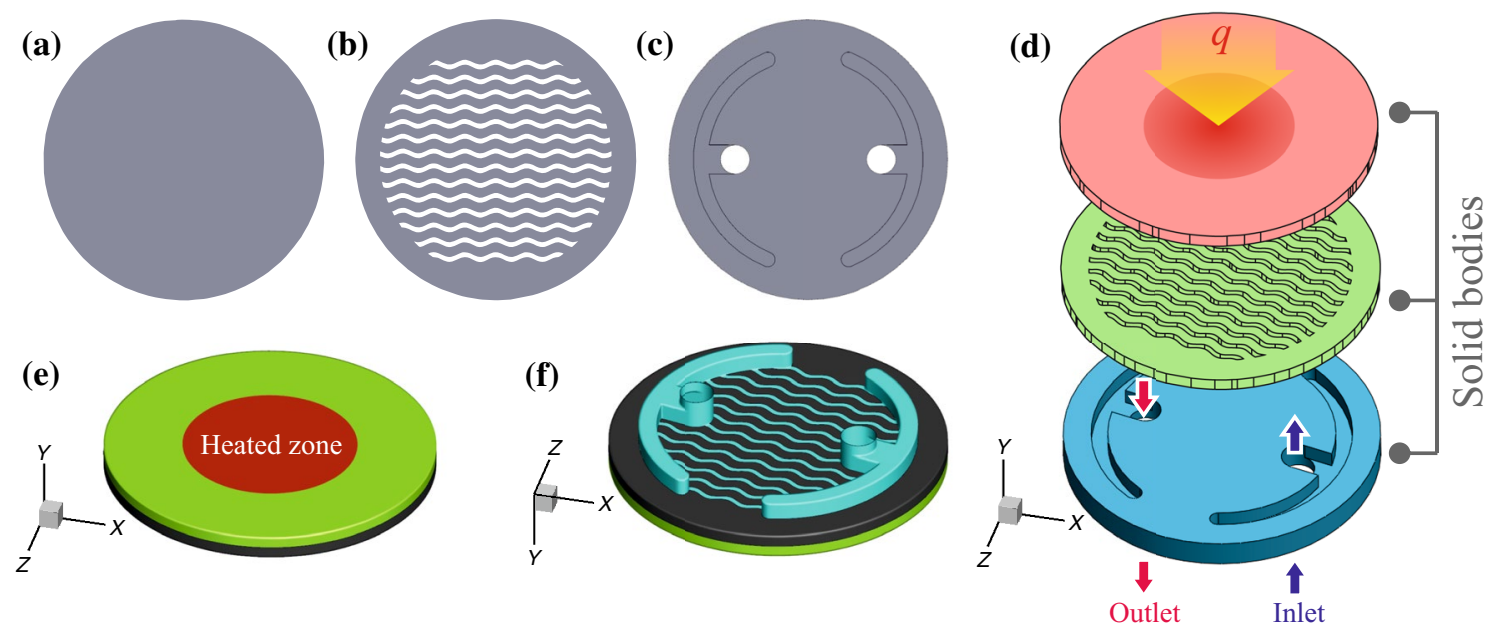

Outlet

Fig. 1 Schematic of the heat sink considered in the present work and the computational domain. The top layer (a), the middle layer (b), and the bottom layer (c) are assembled to build the heat sink (d). A constant uniform heat flux is applied to a circular region on the upper surface of the top layer (the red region in sub-figure (e)). Heat conduction in the bottom layer is neglected as shown in sub-figure (f)

\section{Mathematical formulation and boundary conditions}

The liquid coolants are assumed to be incompressible and Newtonian with temperature-dependent material properties. Since the nanoparticle volume fractions are less than $4 \%$ and their sizes are smaller than $100 \mathrm{~nm}$, a single-phase approach is utilised [36]. Using the single-phase approach avoids unnecessary computational costs associated with two-phase approaches while it results in the same level of accuracy [10]. The fluid flow is assumed to be laminar, and the effects of radiation and gravity are ignored. The surface roughness of the heat sink is deemed to be negligible. The steady-state continuum equations of mass, momentum and energy conservation are cast, respectively, as follows:

$\frac{\partial\left(\rho \cdot u_{\mathrm{i}}\right)}{\partial x_{\mathrm{i}}}=0$

$\frac{\partial\left(\rho \cdot u_{\mathrm{i}} \cdot u_{\mathrm{j}}\right)}{\partial x_{\mathrm{i}}}=-\frac{\partial p}{\partial x_{\mathrm{i}}}+\frac{\partial}{\partial x_{\mathrm{i}}}\left(\mu \frac{\partial u_{\mathrm{j}}}{\partial x_{\mathrm{i}}}\right)$
Table 1 Thermophysical properties of silicon, base fluid and nanoparticles used in the present work

\begin{tabular}{lllll}
\hline Property & Silicon [52] & Base fluid [10] & $\mathrm{Al}_{2} \mathrm{O}_{3}[10]$ & Unit \\
\hline Density $\rho$ & 2330 & 1000 & 3970 & $\mathrm{~kg} \mathrm{~m}^{-3}$ \\
Specific heat capacity $c_{\mathrm{p}}$ & $390+0.9 \cdot T$ & 4180 & 765 & $\mathrm{~J} \mathrm{~kg}^{-1} \mathrm{~K}^{-1}$ \\
Thermal conductivity $k$ & $290-0.4 \cdot T$ & $0.6 \cdot\left(1+4.167 \times 10^{-5} \cdot T\right)$ & 36 & $\mathrm{~W} \mathrm{~m}^{-1} \mathrm{~K}^{-1}$ \\
Viscosity $\mu$ & - & $2.761 \times 10^{-6} \cdot \exp (1713 / T)$ & - & $\mathrm{kg} \mathrm{m}^{-1} \mathrm{~s}^{-1}$ \\
\hline
\end{tabular}


$\frac{\partial\left(\rho \cdot c_{\mathrm{p}} \cdot u_{\mathrm{i}} \cdot T\right)}{\partial x_{\mathrm{i}}}=\frac{\partial}{\partial x_{\mathrm{i}}}\left(k \frac{\partial T}{\partial x_{\mathrm{i}}}\right)+\psi$,

where $\vec{u}$ is the fluid velocity vector, $\rho$ density, $p$ static pressure, $\mu$ dynamic viscosity, $c_{\mathrm{p}}$ specific heat capacity, $T$ temperature, $k$ thermal conductivity and $\psi$ the dissipation function defined as:

$\psi=\left[\frac{\partial\left(\mu \cdot u_{\mathrm{i}}\right)}{\partial x_{\mathrm{j}}}+\frac{\partial\left(\mu \cdot u_{\mathrm{j}}\right)}{\partial x_{\mathrm{i}}}\right] \frac{\partial\left(\mu \cdot u_{\mathrm{i}}\right)}{\partial x_{\mathrm{j}}}$.

The density of the nanofluid is calculated using the mixture model as follows:

$\rho_{\mathrm{nf}}=(1-\phi) \rho_{\mathrm{bf}}+\phi \rho_{\mathrm{np}}$,

where $\phi$ is the nanoparticle volume fraction and the subscripts np, nf and bf stand for nanoparticle, nanofluid and base fluid, respectively. Assuming thermal equilibrium between the base fluid and nanoparticles, the specific heat capacity of the nanofluid is determined as follows [53]:

$c_{\mathrm{p}_{\mathrm{nf}}}=\frac{(1-\phi)\left(\rho c_{\mathrm{p}}\right)_{\mathrm{bf}}+\phi\left(\rho c_{\mathrm{p}}\right)_{\mathrm{np}}}{(1-\phi) \rho_{\mathrm{bf}}+\phi \rho_{\mathrm{np}}}$.

A validated model proposed by Koo and Kleinstreuer [46, 47] is used here to approximate the effective temperaturedependent thermal conductivity of nanofluids. Accordingly, the effective thermal conductivity is assumed to have a static part and a dynamic part [54]. The static part is obtained using the Hamilton-Crosser model [41] and the dynamic part using the kinetic theory. This model is valid for $\phi \leq 4 \%$ and $300 \mathrm{~K} \leq T \leq 325 \mathrm{~K}[47,49]$ and is expressed as:

$k_{\mathrm{nf}}=k_{\text {static }}+k_{\text {Brownian }}$,

$k_{\text {static }}=k_{\mathrm{bf}}\left[\frac{\left(k_{\mathrm{np}_{\mathrm{eff}}}+2 k_{\mathrm{bf}}\right)+2 \phi\left(k_{\mathrm{np}_{\mathrm{eff}}}-k_{\mathrm{bf}}\right)}{\left(k_{\mathrm{np}_{\mathrm{eff}}}+2 k_{\mathrm{bf}}\right)-\phi\left(k_{\mathrm{np}_{\mathrm{eff}}}-k_{\mathrm{bf}}\right)}\right]$,

$k_{\text {Brownian }}=5 \times 10^{4} \phi c_{\mathrm{p}_{\mathrm{bf}}} \rho_{\mathrm{bf}} \sqrt{\frac{\kappa T}{d_{\mathrm{np}} \rho_{\mathrm{np}}}} f\left(T, \phi, d_{\mathrm{np}}\right)$,

where $d_{\mathrm{np}}$ is the nanoparticle diameter and $\kappa$ the Boltzmann

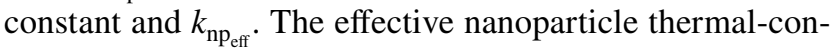
ductivity $k_{\mathrm{np}_{\mathrm{eff}}}$ is calculated by taking the interfacial thermal resistance between nanoparticles and the surrounding liquid into account and is defined as:

$k_{\mathrm{np} \text { eff }}=\frac{d_{\mathrm{np}}}{R_{\mathrm{b}}+\left(\frac{d_{\mathrm{np}}}{k_{\mathrm{np}}}\right)}$.
In the above, $R_{\mathrm{b}}$ is the Kapitza resistance [55] and chosen to be $4 \times 10^{-8} \mathrm{~K} \mathrm{~m}^{2} \mathrm{~W}^{-1}[49,56]$. The empirical function $f$ is developed to take the interaction between particles into consideration based on experimental data sets of water-based nanofluids $[49,54]$ and is defined as follows:

$$
\begin{aligned}
f= & {\left[a_{1}+a_{2} \ln \left(d_{\mathrm{np}}\right)+a_{3} \ln (\phi)\right.} \\
& \left.+a_{4} \ln \left(d_{\mathrm{np}}\right) \ln (\phi)+a_{5} \ln ^{2}\left(d_{\mathrm{np}}\right)\right] \ln (T) \\
& +\left[a_{6}+a_{7} \ln \left(d_{\mathrm{np}}\right)+a_{8} \ln (\phi)\right. \\
& \left.+a_{9} \ln \left(d_{\mathrm{np}}\right) \ln (\phi)+a_{10} \ln ^{2}\left(d_{\mathrm{np}}\right)\right],
\end{aligned}
$$

where $a_{1}$ to $a_{10}$ are constants that their values are reported in [54] for water-based nanofluids containing $\mathrm{Al}_{2} \mathrm{O}_{3}$ and $\mathrm{CuO}$ nanoparticles. Similarly, the effective viscosity of nanofluids $\mu_{\mathrm{nf}}$ is approximated with

$\mu_{\mathrm{nf}}=\mu_{\text {static }}+\mu_{\text {Brownian }}$,

where $\mu_{\text {static }}$ and $\mu_{\text {Brownian }}$ are the static part and the dynamic part of the effective viscosity, respectively, and are defined as:

$\mu_{\text {static }}=\frac{\mu_{\mathrm{bf}}}{(1-\phi)^{2.5}}$,

$\mu_{\text {Brownian }}=5 \times 10^{4} \phi \rho_{\mathrm{bf}} \sqrt{\frac{\kappa T}{d_{\mathrm{np}} \rho_{\mathrm{np}}}} f\left(T, \phi, d_{\mathrm{np}}\right)$.

Reliability of the present model in approximating the thermophysical properties of water- $\mathrm{Al}_{2} \mathrm{O}_{3}$ and water-CuO nanofluids has been verified for various benchmark cases [10, 48, 57].

A constant uniform heat flux $(q)$ is applied to a circular region with a diameter of $30 \mathrm{~mm}$ on the top surface of the heat sink. Regions outside the heated region are modelled as adiabatic walls. The coolant enters to the heat sink with a constant and uniform velocity normal to the inlet boundary and a fixed temperature of $300 \mathrm{~K}$. The outlet gauge pressure is set to $0 \mathrm{pa}$. No-slip boundary condition is applied to the all solid walls.

\section{Numerical procedure and data reduction}

The finite-volume approach is employed to discretise the governing equations. The computational domain is discretised using an unstructured grid with non-uniform tetrahedron cells and is shown in Fig. 2. Smaller cell sizes are employed in the cooling channels compared with those in the solid regions. The second-order upwind scheme is utilised for the discretisation of the convective and diffusive terms of the governing equations. The pressure-velocity coupling is treated using the SIMPLEC [58] algorithm. 
Fig. 2 The computational grid used in the present work to calculate the heat and fluid flow fields

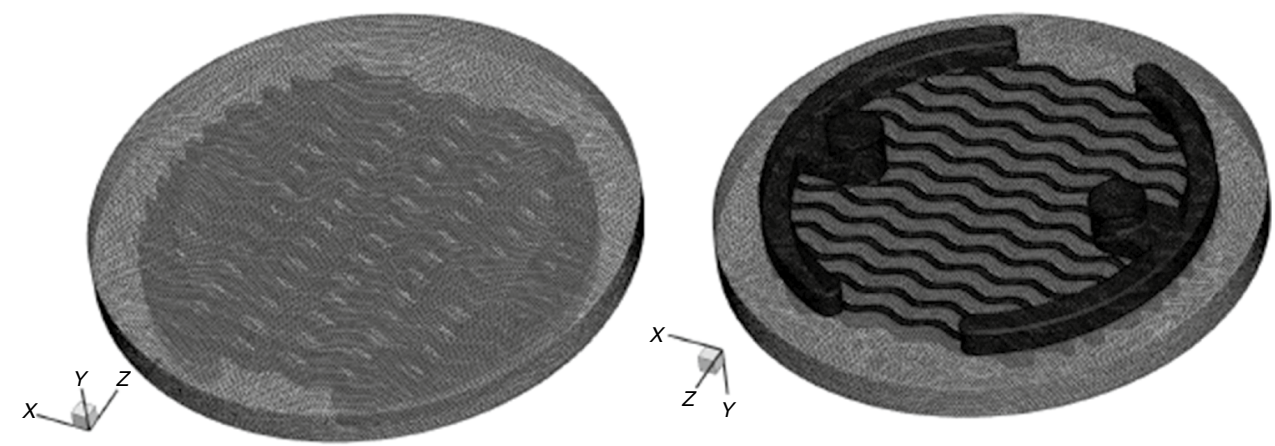

The convergence criterion is to reach scaled residuals of less than $10^{-7}, 10^{-7}$ and $10^{-9}$ for the continuity, momentum and energy equations, respectively. The numerical model is built on the framework of a commercial solver (ANSYS Fluent [59]), and the calculations are performed in parallel on four cores of an Intel Core i7-3520M processor. User-defined functions are programmed using the $\mathrm{C}$ programming language to calculate temperature-dependent thermophysical properties of the nanofluids.

The following parameters are used to present the results obtained from the simulations. The Reynolds number (Re) based on the channel hydraulic diameter $\left(D_{\mathrm{h}}\right)$ is defined as:

$\operatorname{Re}=\frac{\rho_{\mathrm{i}}|\vec{u}|_{\mathrm{i}} D_{\mathrm{h}}}{\mu_{\mathrm{i}}}$,

where subscript $i$ indicates the inlet condition. The heat transfer coefficient $(h)$ is defined as:

$h=\frac{q}{T_{\mathrm{w}, \mathrm{m}}-\left(T_{\mathrm{i}}+T_{\mathrm{o}}\right) / 2}$,

wherein $T_{\mathrm{w}, \mathrm{m}}$ is the average temperature of the top surface. The pumping power required to drive the fluid flow in the heat sink $\left(P_{\mathrm{p}}\right)$ is calculated as follows:

$P_{\mathrm{p}}=Q \cdot \Delta p$,

where $Q$ is volumetric flow rate and $\Delta p$ the pressure drop in the heat sink, which is calculated as follows:

$\Delta p=\bar{p}_{\mathrm{i}}-\bar{p}_{\mathrm{o}}$.

In the above, $\bar{p}$ is the averaged static pressure. Then, the thermo-hydraulic performance criterion can be defined as follows to compare different designs [60-62]:

$j=\frac{h / h_{\text {ref }}}{\left(P_{\mathrm{p}} / P_{\mathrm{p}_{\mathrm{ref}}}\right)^{1 / 3}}$,

where the subscript ref shows the reference design which is the water cooled heat sink with straight channel walls.

\section{Results and discussion}

\section{Grid study and solver verification}

Sensitivity of the numerical results to the grid size is investigated for a water-cooled heat sink with corrugated channels at $\operatorname{Re}=600$, and the results are presented in Table 2. The average temperature of the heat sink top surface $\left(\bar{T}_{\text {top surface }}\right)$ and pressure drop across the heat sink $(\Delta p)$ for each grid are compared with those of the finest grid (i.e. the mesh with approximately $1.1 \mathrm{e} 6$ cells). The difference between the predicted values of $\bar{T}_{\text {top surface }}$ and $\Delta p$ using the grids with 1.1e6 and $9.3 \mathrm{e} 5$ cells are not significant. Accordingly, a mesh containing 930476 cells is utilised for numerical calculations.

Accuracy and reliability of the present model in predicting heat and fluid flow in micro- and mini-channels have been verified in the previous studies conducted by the authors for both water and nanofluids [9, 10, 63-65]. Further verification of the model has been performed considering the experimental and numerical data reported by Sui et al. [66] for deionised water flow in a micro-channel heat sink with sixty corrugated channels in the range of Reynolds number between 300 and 800 . In the reference case, the bottom surface of the heat sink is imposed to a constant heat flux of $50 \mathrm{~W} \mathrm{~cm}^{-2}$ and each channel has a rectangular cross-section and a hydraulic diameter of $272 \mu \mathrm{m}$. Corrugated channel walls with a thickness of $195 \mu \mathrm{m}$ in sinusoidal

Table 2 Sensitivity of the numerical predictions to the grid size

\begin{tabular}{lllll}
\hline Number of cells & $\bar{T}_{\text {top surface }} / \mathrm{K}$ & $\begin{array}{l}\text { Diff. } \\
\bar{T}_{\text {top surface }} \\
\end{array}$ & $\Delta p / \mathrm{pa}$ & Diff. $\Delta p / \%$ \\
\hline 608,564 & 302.14 & 0.11 & 1220.3 & -2.9 \\
659,128 & 302.08 & 0.09 & 1226.9 & -2.3 \\
752,541 & 301.95 & 0.05 & 1239.4 & -1.3 \\
930,476 & 301.85 & 0.02 & 1251.1 & -0.4 \\
$1,114,543$ & 301.80 & - & 1256.2 & - \\
\hline
\end{tabular}

The water-cooled heat sink with corrugated channels at $\operatorname{Re}=600$ is considered for the grid independence study 
shape with a wavelength and an amplitude of $2.5 \mathrm{~mm}$ and $138 \mu \mathrm{m}$, respectively, are considered. More information on experimental conditions can be found in the reference [66]. The mean Nusselt number $\left(\mathrm{Nu}=h D_{\mathrm{h}} / k\right)$ and friction factor $\left(f=2 \Delta p D_{\mathrm{h}} /\left(\rho|\vec{u}|_{\mathrm{i}}^{2}\right)\right)$ obtained from the present model are compared with the reference data in Fig. 3. The mean deviation between the predicted and experimentally measured values of Nusselt number and friction factor is found to be less than $8 \%$, which reveals a reasonable agreement.

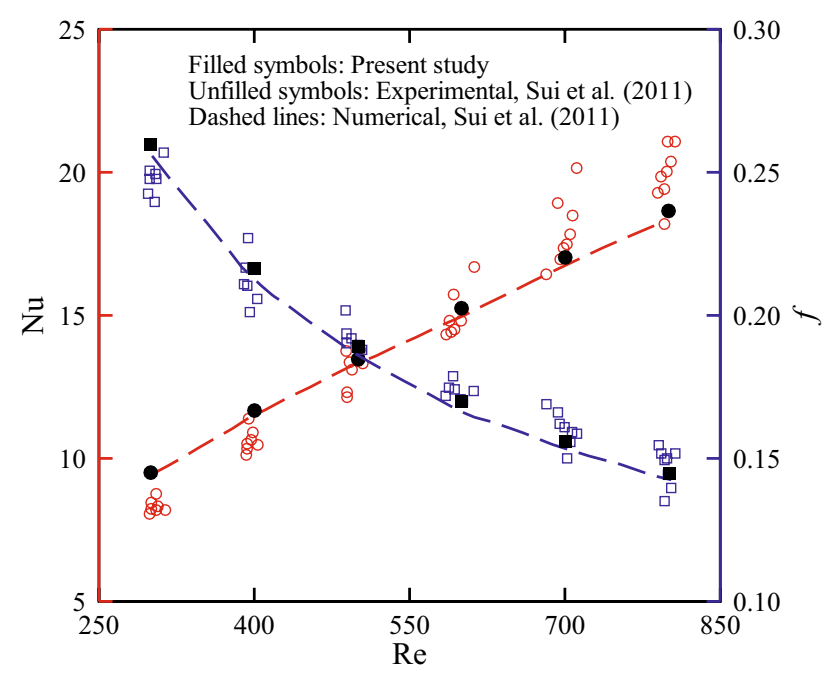

Fig. 3 Comparison of the numerical results obtained from the present model (filled symbols) with the experimental (unfilled symbols) and numerical data (dashed lines) reported by [66] for a microchannel heat sink with corrugated channels. Circles: mean Nusselt number $(\mathrm{Nu})$ and squares: friction factor $(f)$

\section{The effect of employing corrugated channels}

Figure 4 shows the influence of channel configuration on thermo-hydraulic performance of the heat sinks at different coolant mass-flow rates. Regardless of the channel configuration, the averaged heat transfer coefficient $h$ increases with increasing the coolant mass-flow rate at the cost of higher pumping power $P_{\mathrm{p}}$. Thermal boundary layer thickness in the channel decreases with an increase in the coolant mass flow rate, and thus the temperature gradient increases close to the channel walls resulting in higher heat transfer. Replacing straight channels with corrugated channels in the heat sink results in an increase of $24-36 \%$ in averaged heat transfer coefficient $h$ and $20-31 \%$ in required pumping power $P_{\mathrm{p}}$.

Contours of velocity magnitude are shown in Fig. 5 for the case of water flow in corrugated channels at $\mathrm{Re}=600$ as a representative case. Tangential velocity vectors shown at the channel cross-section in Fig. 5a indicate the formation of secondary-flow in corrugated channels. A similar flow pattern is observed for other cases with corrugated channels studied in the present work. Fluid flow passing through channels with corrugated walls is exposed to a centrifugal force disturbing the flow field that can lead to fluid recirculation $[67,68]$. Because of fluid recirculation, a secondary flow is induced in the channel that moves the fluid from the central region of the channel towards its hot walls and back from the regions adjacent to the channel walls towards the central region of the channel. This centrifugal force, thus the strength of the secondary flow, increases with increasing the Reynolds number. Additionally, changes in the curvature of the channel walls result in changes in the direction of the vortices generated in the channel. The enhancement of thermal performance in the heat sink with corrugated channels is attributed to the augmentation of heat transfer area
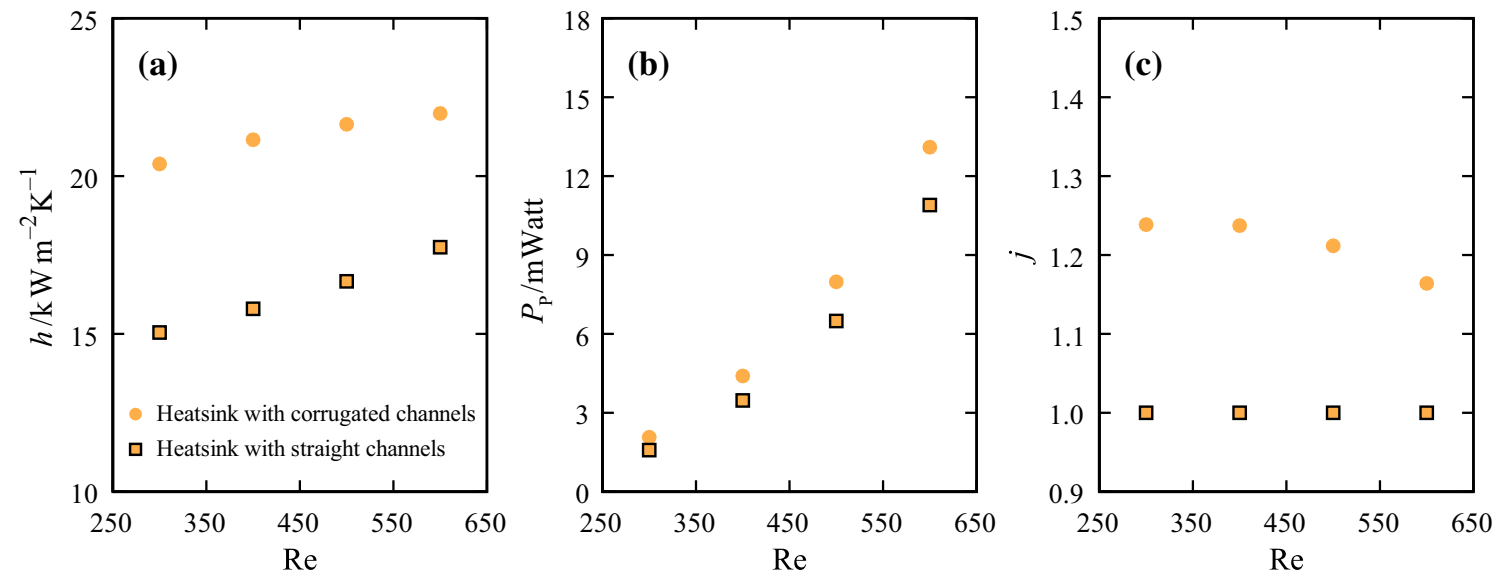

Fig. 4 The effect of the channel configuration on the thermal and hydraulic performance of the heat sink. Variations of the heat transfer coefficient (a), the required pumping power to drive the coolant (b), and the overall performance of the heat sink (c) as a function of Reynolds number 


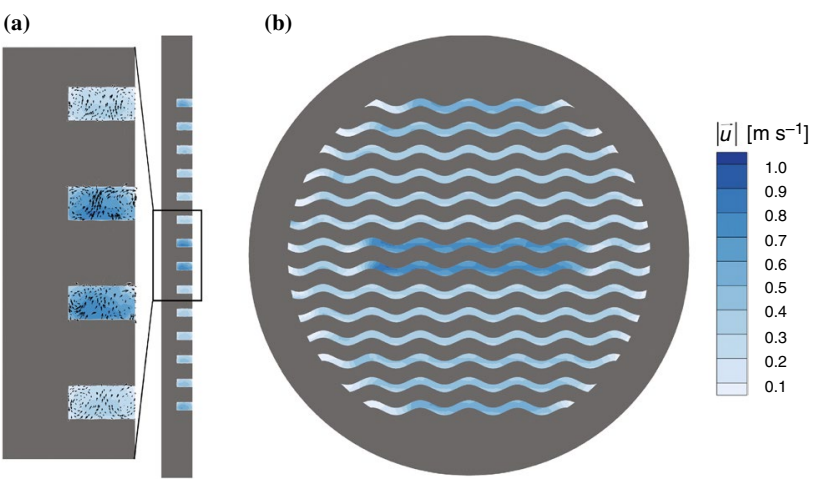

Fig. 5 Contours of velocity magnitude shown on a a plane normal to the $x$-axis passing through the heat sink centre and $\mathbf{b}$ a plane normal to the $y$-axis and located at the middle of the heat sink middle layer (Fig. 1b). Velocity vectors indicate the formation of secondary flow in corrugated channels. Coolant: water, $\mathrm{Re}=600$

and the formation of secondary-flow vortices that intensifies convection.

Secondary flow generated in corrugated channels and the interactions between the vortices and the channel walls also increase pressure losses in the heat sink. Taking both thermal and hydraulic performances into consideration, the overall performance $j$ of a heat sink with corrugated channels enhances by $16-24 \%$ compared with its corresponding heat sink with straight channels. Although the overall performance of the heat sink with corrugated channels is higher than that of the heat sink with straight channels, its overall performance decreases with the Reynolds number because of the augmentation of pressure losses at higher Reynolds numbers. It should be noted that the geometrical configuration of the corrugated channels (e.g. wavelength and amplitude) affects the performance of the heat sink, which have been discussed in previous studies conducted by others [15, $24,69,70]$ and thus are not repeated here.

Temperature distribution over the heat sink surface is presented in Fig. 6 for different configurations and coolant mass flow rates. The temperatures predicted for the heat sink with corrugated channels are lower than those of the heat sink with straight channels. Additionally, the maximum temperature over the heat sink surface for the heat sink with straight channels at $\mathrm{Re}=600$ is comparable with that of a heat sink with corrugated channels at $\mathrm{Re}=300$. Low coolant mass flow rates are desirable to weaken the vibrations that may occur due to the fluid flow in the heat sink [50]. However, the performance of the heat sink at low Reynolds numbers is limited because of the poor thermal conductivity of the coolant employed in the heat sink (i.e. water). Nanofluids generally have higher thermal conductivities in comparison with common liquid coolants (e.g. water and organic chemicals) and are often considered as a reasonable alternative working fluid for heat-removal applications due to their improved thermal properties. The influence of utilising nanofluids on thermal and hydraulic performance of the heat sink with corrugated channels is reported in "The effect of utilising nanofluids as the coolant" section.

\section{The effect of utilising nanofluids as the coolant}

Figure 7 shows the influence of employing water- $\mathrm{Al}_{2} \mathrm{O}_{3}$ nanofluids with different nanoparticle sizes $d_{\mathrm{np}}$ and volume fractions $\phi$ as the coolant on the thermal and hydraulic performance of the heat sink at different Reynolds numbers. The heat transfer coefficients $h$ attained for the cases that utilise nanofluids as the coolant are higher than those of the cases that water is employed to cool the heat sink. This is mainly due to the higher effective thermal conductivity of nanofluids in comparison with that of the base fluid, which results in the enhancement of heat conduction contribution to the total energy transfer. According to Eqs. (7) to (9), thermal conductivity of nanofluids depends on bulk fluid temperature and nanoparticle volume fraction, size and material. The heat transfer performance of the heat sink increases with increasing the nanoparticles volume fraction $\phi$. This is due to the increase in total heat transfer area between the particles and the base fluid, and the enhancement of nanoparticle collision rate that intensifies the Brownian motion of particles resulting in the enhancement of the effective thermal conductivity of the mixture.

Figure $7 \mathrm{~b}$ demonstrates that the enhancement of heat transfer performance of the heat sink achieved using nanofluids is associated with higher pressure losses. This is because of the higher effective viscosity of nanofluids compared to that of the base fluid (see Eqs. (12) to (14)). Interactions between nanoparticles augment with increasing nanoparticle volume fraction $\phi$ leading to an increase in the effective viscosity of the nanofluids $\mu_{\mathrm{nf}}$. Thus, the pumping power required to drive the coolant in the heat sink increases with increasing nanoparticle volume fraction $\phi$.

Nanoparticle size affects the thermophysical properties of nanofluids [36], and thus the thermal and hydraulic performance of the heat sink. Figure 7 shows the influence of nanoparticle size on the thermal and hydraulic performance of the heat sink. Increasing the average size of $\mathrm{Al}_{2} \mathrm{O}_{3}$ nanoparticles from 29 to $40 \mathrm{~nm}$ results in a decrease in the heat transfer performance of the heat sink. For a fixed nanoparticle volume fraction $\phi$, increasing the nanoparticle size $d_{\text {np }}$ results in a reduction of total heat transfer surface area between the particles and their surrounding liquid. Moreover, the Brownian motion of nanoparticle weakens with increasing the particle size $d_{\mathrm{np}}$ that leads to a decrease in the strength of micro-mixing in the base fluid and, thus, the effective thermal conductivity nanofluid. The results 


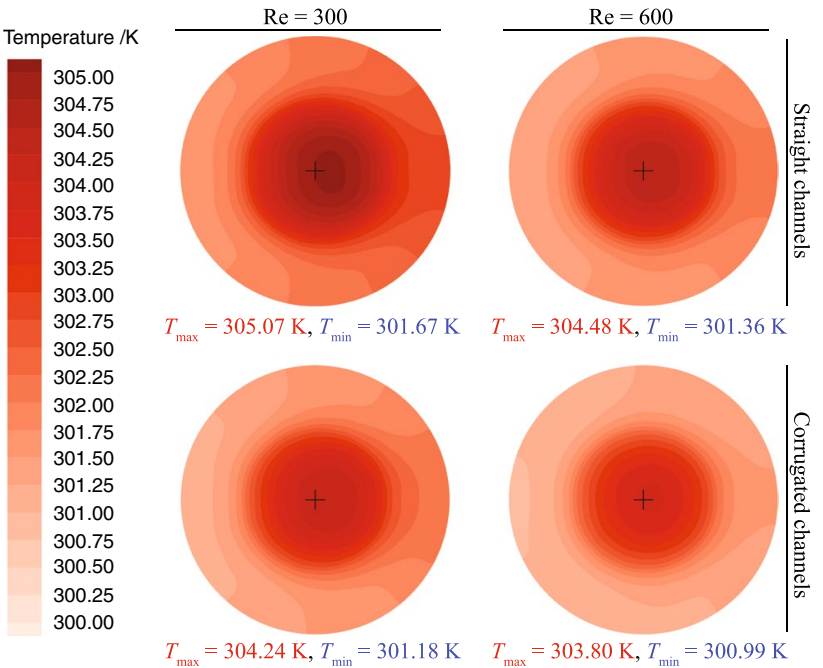

Fig. 6 The influence of the channel configuration in the heat sink and the coolant mass flow rate on temperature distribution over the heat sink surface. The plus mark indicates the location of the heat sink surface centroid

presented in Fig. $7 \mathrm{~b}$ reveal that the required pumping power decreases with increasing the size of $\mathrm{Al}_{2} \mathrm{O}_{3}$ nanoparticles. This can be attributed to the decrease in the number of nanoparticles dispersed in the based fluid that results in a reduction of hydrodynamic interactions between particles and, therefore, the effective viscosity of the nanofluid.

The overall performance of the heat sink is a function of both thermal and hydraulic performances, as expressed in Eq. (19). Compared with the water-cooled heat sink with straight channels, the overall performance of the heat sink (j) with corrugated channels increases by $22-40 \%$, for the range of parameters studied in the present work, using water- $\mathrm{Al}_{2} \mathrm{O}_{3}$ nanofluids (see Fig. 7c). The overall performance of the heat sink enhances with increasing the nanoparticle volume fraction $\phi$ and decreases with increasing the size of $\mathrm{Al}_{2} \mathrm{O}_{3}$ nanoparticles.

Temperature distributions predicted over the heat sink surface using water and nanofluids with different nanoparticle volume fractions and different mass flow rates are presented in Fig. 8. Due to the higher effective thermal conductivity of nanofluids compared with that of the base fluid (water), the values of temperature and their spatial gradient over the heat sink surface are lower, which is desirable to reduce thermal deformations of the heat sink surface. Additionally, the maximum temperature of the heat sink surface decreases with increasing the nanoparticle volume fraction $\phi$ (see Fig. 8).

The performance of the proposed design is systematically studied for different thermal loads, and the results are presented in Fig. 9. The thermal load is increased step-by-step to determine the threshold that the maximum temperaturerise in the heat sink reaches $25 \mathrm{~K}$. The maximum temperature-rise in the heat $\operatorname{sink} T_{\text {rise }}$ appears to be a linear function of the heat flux applied to its surface $q$. For a maximum temperature rise of $25 \mathrm{~K}$ and in comparison with the watercooled heat sink with straight channels, the thermal load can be increased by $50 \%$ to $q=255 \mathrm{~kW} \mathrm{~m}^{-2}$ by employing the design with corrugated channels and water $-\mathrm{Al}_{2} \mathrm{O}_{3}$ nanofluid with $\phi=3 \%$ and $d_{\mathrm{np}}=29 \mathrm{~nm}$.

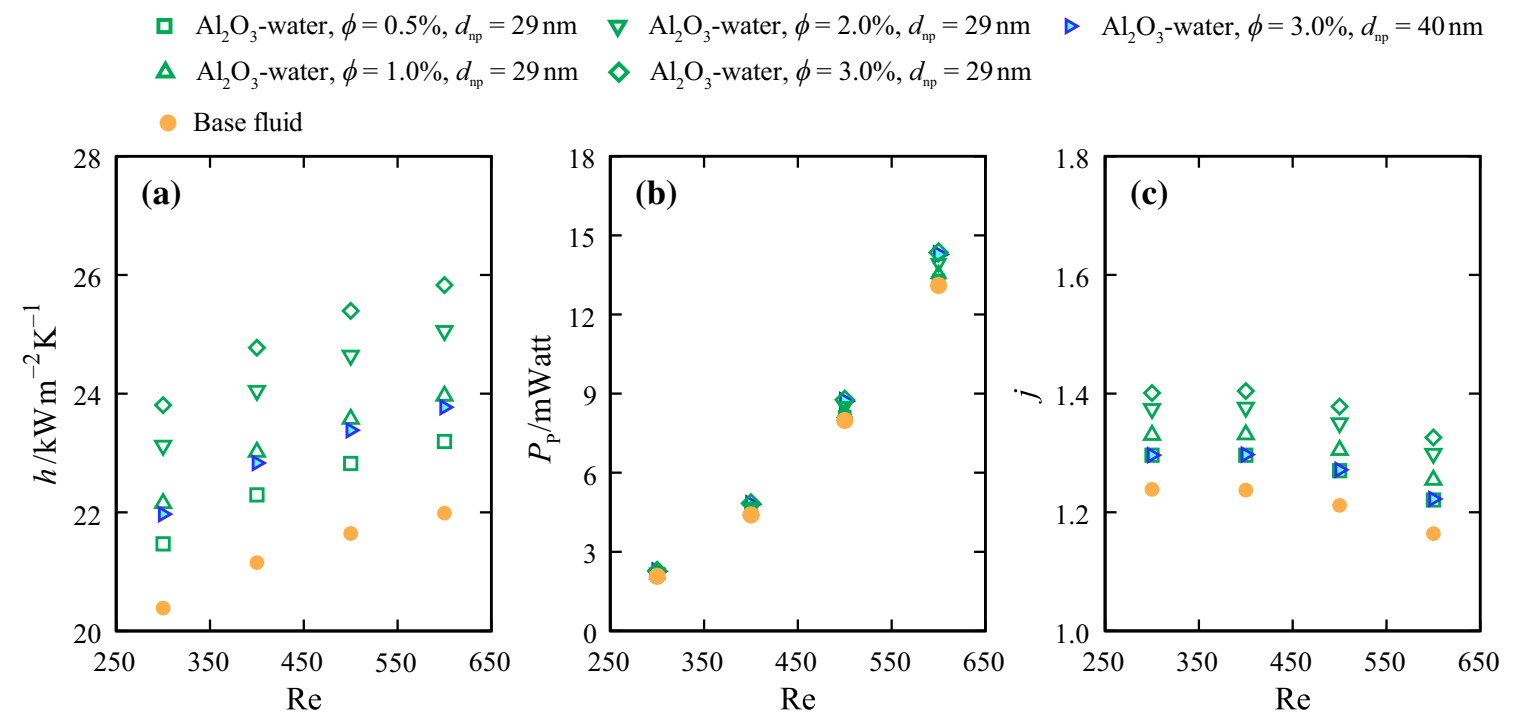

Fig. 7 The influence of employing nanofluids, with different nanoparticle volume fractions $\phi$ and sizes $d_{\text {np }}$, on the thermal and hydraulic performance of the heat sink with corrugated channels. Variations of the heat transfer coefficient (a), the required pumping power to drive the coolant (b), and the overall performance of the heat sink (c) as a function of Reynolds number 


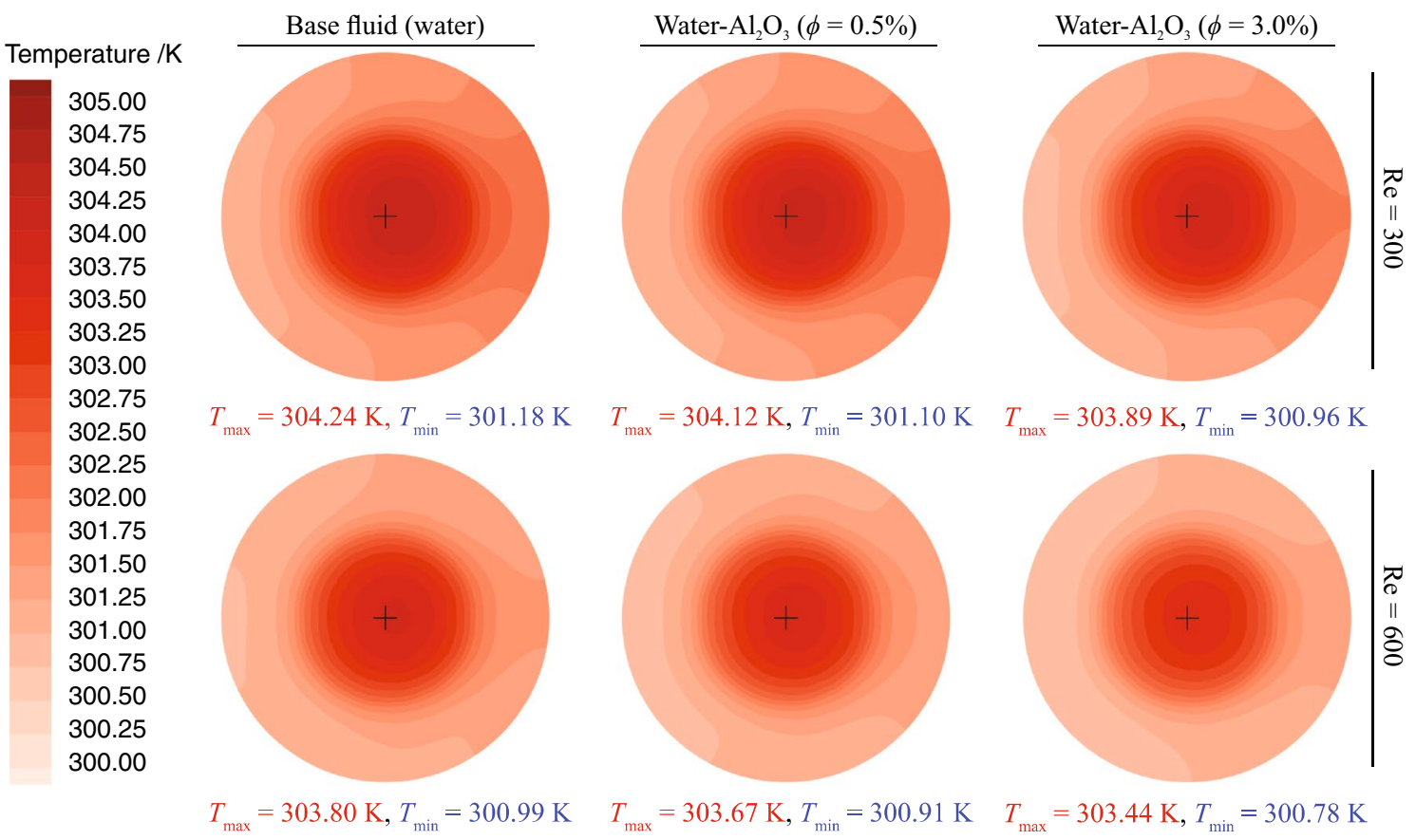

Fig. 8 The influence of employing water and nanofluids with low volume fractions $(\phi=0.5 \%)$ in the heat sink and their mass flow rate on surface temperature of the heat sink. Nanoparticle size $\left(d_{\mathrm{np}}\right)$ for both

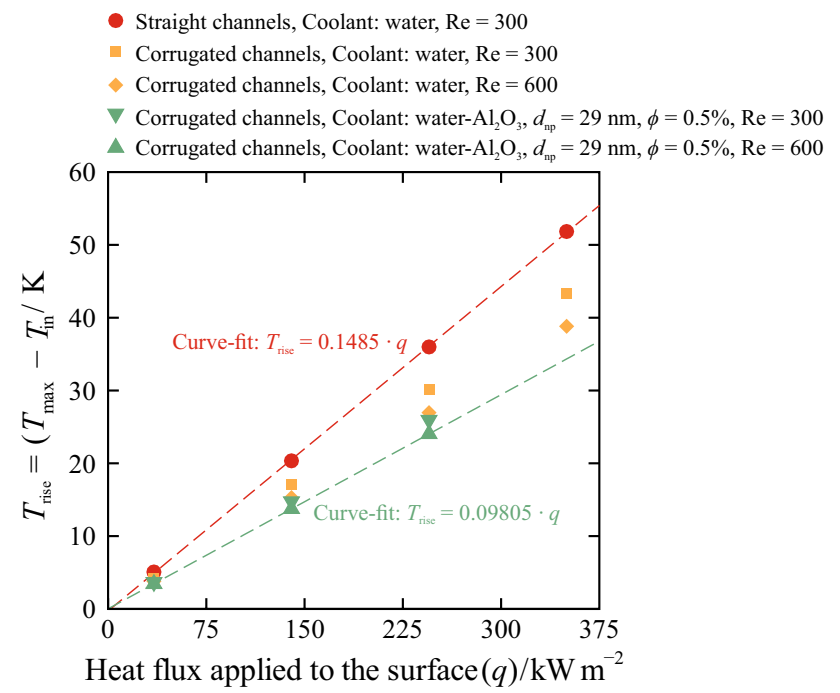

Fig. 9 The maximum temperature-rise in the heat sink as a function of thermal load. Symbols: numerical predictions obtained from simulations. Dashed-lines: linear curve-fits

\section{Conclusions}

Three-dimensional simulations were performed to investigate conjugated heat transfer in heat sinks with various configurations and coolants. The effects of utilising corrugated channels and water- $\mathrm{Al}_{2} \mathrm{O}_{3}$ nanofluids with different volume nanofluids is set to $29 \mathrm{~nm}$. The plus mark indicates the location of the heat sink surface centroid

fractions and nanoparticle sizes were studied for different coolant mass flow rates. Additionally, the influence of different heat loads on maximum temperature rise in the heat sink was investigated and semi-empirical correlations were introduced for the proposed design. Based on the results obtained from the simulations, the following conclusions are drawn.

Because of the formation of secondary flow and the augmentation of heat transfer surface area, the thermo-hydraulic performance of the heat sink increases using corrugated channels. However, this enhancement in heat transfer performance is associated with larger pressure penalties. For the range of Reynolds numbers considered in the present work $(300 \leq \operatorname{Re} \leq 600)$, employing corrugated channels instead of straight channels in the heat sink results in a heat transfer enhancement of 24-36\%, while the required pumping power increases by $20-31 \%$ resulting in an overall performance improvement of 20-31\%. Employing water-based nanofluids that contain $\mathrm{Al}_{2} \mathrm{O}_{3}$ nanoparticles with different sizes ( $29 \mathrm{~nm}$ and $29 \mathrm{~nm}$ ) and volume fractions less than $3 \%$, the overall performance of the heat sink increases by $22-40 \%$ in comparison with the water-cooled heat sink with straight channels. The overall performance of the heat sink enhances with increasing nanoparticle volume fraction and reducing the average size of nanoparticles in water $-\mathrm{Al}_{2} \mathrm{O}_{3}$ nanofluids. The results obtained from the present numerical simulations demonstrate that the proposed design with corrugated channels and water- $\mathrm{Al}_{2} \mathrm{O}_{3}$ nanofluid with $\phi=3 \%$ 
and $d_{\mathrm{np}}=29 \mathrm{~nm}$ can significantly reduce the heat sink surface temperature for the same thermal load. The proposed heat sink design has higher energy efficiencies at low mass flow rates.

Author contributions A.E. and B.N. were involved in conceptualisation; A.E. and B.N. were involved in methodology; A.E. and B.N. were involved in software; A.E. and B.N. were involved in validation; A.E. and B.N. were involved in formal analysis; A.E. and B.N. were involved in investigation; A.E., B.N. and E.R. were involved in resources; B.N. was involved in data curation; A.E. and B.N. were involved in writing-original draft preparation; A.E., B.N. and E.R. were involved in writing-review and editing; A.E. and B.N. were involved in visualisation; A.E. and E.R. were involved in supervision; and A.E. was involved in project administration.

\section{Compliance with ethical standards}

Conflict of interest The authors declare that they have no conflict of interest.

Open Access This article is licensed under a Creative Commons Attribution 4.0 International License, which permits use, sharing, adaptation, distribution and reproduction in any medium or format, as long as you give appropriate credit to the original author(s) and the source, provide a link to the Creative Commons licence, and indicate if changes were made. The images or other third party material in this article are included in the article's Creative Commons licence, unless indicated otherwise in a credit line to the material. If material is not included in the article's Creative Commons licence and your intended use is not permitted by statutory regulation or exceeds the permitted use, you will need to obtain permission directly from the copyright holder. To view a copy of this licence, visit http://creativecommons.org/licenses/by/4.0/.

\section{References}

1. Moore AL, Shi L. Emerging challenges and materials for thermal management of electronics. Mater Today. 2014;17(4):163-74. https://doi.org/10.1016/j.mattod.2014.04.003.

2. Ebadian MA, Lin CX. A review of high-heat-flux heat removal technologies. J Heat Transf. 2011;133(11):110801. https://doi. org/10.1115/1.4004340.

3. Dixit T, Ghosh I. Review of micro- and mini-channel heat sinks and heat exchangers for single phase fluids. Renew Sustain Energy Rev. 2015;41:1298-311. https://doi.org/10.1016/j. rser.2014.09.024.

4. Naqiuddin NH, Saw LH, Yew MC, Yusof F, Ng TC, Yew MK. Overview of micro-channel design for high heat flux application. Renew Sustain Energy Rev. 2018;82:901-14. https://doi. org/10.1016/j.rser.2017.09.110.

5. Alam T, Kim M-H. A comprehensive review on single phase heat transfer enhancement techniques in heat exchanger applications. Renew Sustain Energy Rev. 2018;81:813-39. https://doi. org/10.1016/j.rser.2017.08.060.

6. Mohammadi A, Koşar A. The effect of arrangement type and pitch ratio on the performance of micro-pin-fin heat sinks. J Therm Anal Calorim. 2019;. https://doi.org/10.1007/s10973-019-08840 -2 .

7. Wang Y, Zhu K, Cui Z, Wei J. Effects of the location of the inlet and outlet on heat transfer performance in pin fin CPU heat sink.
Appl Therm Eng. 2019;151:506-13. https://doi.org/10.1016/j. applthermaleng.2019.02.030.

8. Peles Y, Koşar A, Mishra C, Kuo C-J, Schneider B. Forced convective heat transfer across a pin fin micro heat sink. Int $J$ Heat Mass Transf. 2005;48(17):3615-27. https://doi.org/10.1016/j.jhea tmasstransfer.2005.03.017.

9. Ebrahimi A, Roohi E, Kheradmand S. Numerical study of liquid flow and heat transfer in rectangular microchannel with longitudinal vortex generators. Appl Therm Eng. 2015;78:576-83. https ://doi.org/10.1016/j.applthermaleng.2014.12.006.

10. Ebrahimi A, Rikhtegar F, Sabaghan A, Roohi E. Heat transfer and entropy generation in a microchannel with longitudinal vortex generators using nanofluids. Energy. 2016;101:190-201. https:// doi.org/10.1016/j.energy.2016.01.102.

11. Lu G, Zhai X. Analysis on heat transfer and pressure drop of a microchannel heat sink with dimples and vortex generators. Int $\mathrm{J}$ Therm Sci. 2019;145:105986. https://doi.org/10.1016/j.ijthermals ci.2019.105986.

12. Sui Y, Teo C, Lee P, Chew Y, Shu C. Fluid flow and heat transfer in wavy microchannels. Int J Heat Mass Transf. 2010;53(1314):2760-72. https://doi.org/10.1016/j.ijheatmasstrans fer.2010.02.022

13. Zhu J-F, Li X-Y, Wang S-L, Yang Y-R, Wang X-D. Performance comparison of wavy microchannel heat sinks with wavy bottom rib and side rib designs. Int J Therm Sci. 2019;146:106068. https ://doi.org/10.1016/j.ijthermalsci.2019.106068.

14. Bazdar H, Toghraie D, Pourfattah F, Akbari OA, Nguyen HM, Asadi A. Numerical investigation of turbulent flow and heat transfer of nanofluid inside a wavy microchannel with different wavelengths. J Therm Anal Calorim. 2019;. https://doi.org/10.1007/ s10973-019-08637-3.

15. Khoshvaght-Aliabadi M, Sahamiyan M. Performance of nanofluid flow in corrugated minichannels heat sink (CMCHS). Energy Convers Manag. 2016a;108:297-308. https://doi.org/10.1016/j. enconman.2015.11.026.

16. Goldstein L, Sparrow EM. Heat/mass transfer characteristics for flow in a corrugated wall channel. J Heat Transf. 1977;99(2):187. https://doi.org/10.1115/1.3450667.

17. Elshafei E, Awad M, El-Negiry E, Ali A. Heat transfer and pressure drop in corrugated channels. Energy. 2010;35(1):101-10. https://doi.org/10.1016/j.energy.2009.08.031.

18. Ali MM, Ramadhyani S. Experiments on convective heat transfer in corrugated channels. Exp Heat Transf. 1992;5(3):175-93. https ://doi.org/10.1080/08916159208946440.

19. Mohammed H, Gunnasegaran P, Shuaib N. Numerical simulation of heat transfer enhancement in wavy microchannel heat sink. Int Commun Heat Mass Transf. 2011;38(1):63-8. https://doi. org/10.1016/j.icheatmasstransfer.2010.09.012.

20. Sakanova A, Keian CC, Zhao J. Performance improvements of microchannel heat sink using wavy channel and nanofluids. Int J Heat Mass Transf. 2015;89:59-74. https://doi.org/10.1016/j.ijhea tmasstransfer.2015.05.033.

21. Lin L, Zhao J, Lu G, Wang X-D, Yan W-M. Heat transfer enhancement in microchannel heat sink by wavy channel with changing wavelength/amplitude. Int J Therm Sci. 2017;118:423-34. https ://doi.org/10.1016/j.jithermalsci.2017.05.013.

22. Khoshvaght-Aliabadi M. Influence of different design parameters and al 2 o 3-water nanofluid flow on heat transfer and flow characteristics of sinusoidal-corrugated channels. Energy Convers Manag. 2014;88:96-105. https://doi.org/10.1016/j.encon man.2014.08.042.

23. Khoshvaght-Aliabadi M, Rad SH, Hormozi F. $\mathrm{Al}_{2} \mathrm{O}_{3}$-water nanofluid inside wavy mini-channel with different cross-sections. J Taiwan Inst Chem Eng. 2016a;58:8-18. https://doi.org/10.1016/j. jtice.2015.05.029. 
24. Salami M, Khoshvaght-Aliabadi M, Feizabadi A. Investigation of corrugated channel performance with different wave shapes. J Therm Anal Calorim. 2019; . https://doi.org/10.1007/s10973-01908361-y.

25. Khoshvaght-Aliabadi M, Sahamiyan M, Hesampour M, Sartipzadeh O. Experimental study on cooling performance of sinusoidalwavy minichannel heat sink. Appl Therm Eng. 2016b;92:50-61. https://doi.org/10.1016/j.applthermaleng.2015.09.015.

26. Khoshvaght-Aliabadi M, Sahamiyan M. Performance of nanofluid flow in corrugated minichannels heat sink (CMCHS). Energy Convers Manag. 2016b;108:297-308. https://doi.org/10.1016/j. enconman.2015.11.026.

27. Rashidi MM, Rahbari A, Foroutani S, Rahimipetroudi I. Effects of phase shift and wavy amplitude on the laminar forced convection heat transfer enhancement in corrugated channels using copperwater nano-fluid. J Comput Theor Nanosci. 2016;13(8):4941-8. https://doi.org/10.1166/jctn.2016.5368.

28. Mahian O, Kolsi L, Amani M, Estellé P, Ahmadi G, Kleinstreuer C, Marshall JS, Taylor RA, Abu-Nada E, Rashidi S, Niazmand H, Wongwises S, Hayat T, Kasaeian A, Pop I. Recent advances in modeling and simulation of nanofluid flows-part II: applications. Phys Rep. 2019a;791:1-59. https://doi.org/10.1016/j.physr ep.2018.11.003.

29. Masuda H, Ebata A, Teramae K, Hishinuma N. Alteration of thermal conductivity and viscosity of liquid by dispersing ultrafine particles dispersion of $\mathrm{Al}_{2} \mathrm{O}_{3}, \mathrm{SiO}_{2}$ and $\mathrm{TiO}_{2}$ ultra-fine particles. Netsu Bussei. 1993;7(4):227-33. https://doi.org/10.2963/ jjtp.7.227.

30. Keblinski P, Eastman JA, Cahill DG. Nanofluids for thermal transport. Mater Today. 2005;8(6):36-44. https://doi.org/10.1016/ s1369-7021(05)70936-6.

31. Choi S, Eastman J. Enhancing thermal conductivity of fluids with nanoparticles, vol. 231. San Francisco: American Society of Mechanical Engineers, Fluids Engineering Division (Publication) FED; 1995. p. 99-105.

32. Dondapati RS, Saini V, Verma KN, Usurumarti PR. Computational prediction of pressure drop and heat transfer with cryogen based nanofluids to be used in micro-heat exchangers. Int J Mech Sci. 2017;130:133-42. https://doi.org/10.1016/j.ijmec sci.2017.06.012.

33. Bashirnezhad K, Bazri S, Safaei MR, Goodarzi M, Dahari M, Mahian O, Dalkılıça AS, Wongwises S. Viscosity of nanofluids: a review of recent experimental studies. Int Commun Heat Mass Transf. 2016;73:114-23. https://doi.org/10.1016/j.icheatmasstrans fer.2016.02.005

34. Heris SZ, Ahmadi F, Mahian O. Pressure drop and performance characteristics of water-based $\mathrm{Al}_{2} \mathrm{O}_{3}$ and $\mathrm{CuO}$ nanofluids in a triangular duct. J Dispers Sci Technol. 2013;34(10):1368-75. https ://doi.org/10.1080/01932691.2012.745795.

35. Yiamsawas T, Mahian O, Dalkilic AS, Kaewnai S, Wongwises S. Experimental studies on the viscosity of $\mathrm{TiO}_{2}$ and $\mathrm{Al}_{2} \mathrm{O}_{3}$ nanoparticles suspended in a mixture of ethylene glycol and water for high temperature applications. Appl Energy. 2013;111:40-5. https ://doi.org/10.1016/j.apenergy.2013.04.068.

36. Mahian O, Kolsi L, Amani M, Estellé P, Ahmadi G, Kleinstreuer C, Marshall JS, Siavashi M, Taylor RA, Niazmand H, Wongwises S, Hayat T, Kolanjiyil A, Kasaeian A, Pop I. Recent advances in modeling and simulation of nanofluid flows-part I: fundamentals and theory. Phys Rep. 2019b;790:1-48. https://doi.org/10.1016/j. physrep.2018.11.004.

37. Eastman J, Phillpot S, Choi S, Keblinski P. Thermal transport in nanofluids. Annu Rev Mater Res. 2004;34(1):219-46. https://doi. org/10.1146/annurev.matsci.34.052803.090621.
38. Lee S, Choi SU-S, Li S, Eastman JA. Measuring thermal conductivity of fluids containing oxide nanoparticles. J Heat Transf. 1999;121(2):280. https://doi.org/10.1115/1.2825978.

39. Sheikholeslami M, Arabkoohsar A, Jafaryar M. Impact of a helical-twisting device on the thermal-hydraulic performance of a nanofluid flow through a tube. J Therm Anal Calorim. 2019;139(5):3317-29. https://doi.org/10.1007/s10973-019-08683 $-\mathrm{x}$.

40. Maxwell JC. A treatise on electricity and magnetism. Cambridge: Cambridge University Press; 2009. https://doi.org/10.1017/cbo97 80511709340.

41. Hamilton RL, Crosser OK. Thermal conductivity of heterogeneous two-component systems. Ind Eng Chem Fundam. 1962;1(3):187-91. https://doi.org/10.1021/i160003a005.

42. Jeffrey DJ. Conduction through a random suspension of spheres. Proc R Soc A Math Phys Eng Sci. 1973;335(1602):355-67. https ://doi.org/10.1098/rspa.1973.0130.

43. Davis RH. The effective thermal conductivity of a composite material with spherical inclusions. Int $\mathbf{J}$ Thermophys. 1986;7(3):609-20. https://doi.org/10.1007/bf00502394.

44. Lu S-Y, Lin H-C. Effective conductivity of composites containing aligned spheroidal inclusions of finite conductivity. J Appl Phys. 1996;79(9):6761-9. https://doi.org/10.1063/1.361498.

45. Godson L, Raja B, Lal DM, Wongwises S. Enhancement of heat transfer using nanofluids - an overview. Renew Sustain Energy Rev. 2010;14(2):629-41. https://doi.org/10.1016/j. rser.2009.10.004.

46. Koo J, Kleinstreuer C. A new thermal conductivity model for nanofluids. J Nanopart Res. 2004;6(6):577-88. https://doi. org/10.1007/s11051-004-3170-5.

47. Koo J, Kleinstreuer C. Laminar nanofluid flow in microheatsinks. Int J Heat Mass Transf. 2005;48(13):2652-61. https://doi. org/10.1016/j.ijheatmasstransfer.2005.01.029.

48. Yue Y, Mohammadian SK, Zhang Y. Analysis of performances of a manifold microchannel heat sink with nanofluids. Int $\mathbf{J}$ Therm Sci. 2015;89:305-13. https://doi.org/10.1016/j.ijthermals ci.2014.11.016.

49. Li J, Kleinstreuer C. Thermal performance of nanofluid flow in microchannels. Int J Heat Fluid Flow. 2008;29(4):1221-32. https ://doi.org/10.1016/j.ijheatfluidflow.2008.01.005.

50. Cao H, Chen G. Optimization design of microchannel heat sink geometry for high power laser mirror. Appl Therm Eng. 2010;30(13):1644-51. https://doi.org/10.1016/j.appltherma leng.2010.03.022.

51. He C, Chen B, Hu P, Zhu H. The thermal deformation property of silicon mirror with different porosity fabricated by direct laser sintering. Opt Laser Technol. 2018;106:209-14. https://doi. org/10.1016/j.optlastec.2018.04.013.

52. Glassbrenner CJ, Slack GA. Thermal conductivity of silicon and germanium from $3 \mathrm{~K}$ to the melting point. Phys Rev. 1964;134(4A):A1058-69. https://doi.org/10.1103/physrev.134. a1058.

53. Xuan Y, Roetzel W. Conceptions for heat transfer correlation of nanofluids. Int J Heat Mass Transf. 2000;43(19):3701-7. https:// doi.org/10.1016/s0017-9310(99)00369-5.

54. Li, J. Computational analysis of nanofluid flow in microchannels with applications to micro-heat sinks and bio-MEMS. PhD dissertation, Mechanical Engineering, North Carolina State University, Raleigh, North Carolina, USA. 2008. http://www.lib.ncsu. edu/resolver/1840.16/4749.

55. Pollack GL. Kapitza resistance. Rev Mod Phys. 1969;41(1):48-81. https://doi.org/10.1103/revmodphys.41.48.

56. Wilson OM, Hu X, Cahill DG, Braun PV. Colloidal metal particles as probes of nanoscale thermal transport in fluids. Phys Rev B. 2002;. https://doi.org/10.1103/physrevb.66.224301. 
57. Seyf HR, Mohammadian SK. Thermal and hydraulic performance of counterflow microchannel heat exchangers with and without nanofluids. J Heat Transf. 2011;133(8):081801. https://doi. org/10.1115/1.4003553.

58. Doormaal JPV, Raithby GD. Enhancements of the simple method for predicting incompressible fluid flows. Numer Heat Transf. 1984;7(2):147-63. https://doi.org/10.1080/01495728408961817.

59. ANSYS® Fluent, Release 17.0.

60. Ghahremannezhad A, Vafai K. Thermal and hydraulic performance enhancement of microchannel heat sinks utilizing porous substrates. Int J Heat Mass Transf. 2018;122:1313-26. https://doi. org/10.1016/j.ijheatmasstransfer.2018.02.024.

61. Wang B, Hong Y, Wang L, Fang X, Wang P, Xu Z. Development and numerical investigation of novel gradient-porous heat sinks. Energy Convers Manag. 2015;106:1370-8. https://doi. org/10.1016/j.enconman.2015.10.071.

62. Hung T-C, Huang Y-X, Yan W-M. Thermal performance analysis of porous-microchannel heat sinks with different configuration designs. Int J Heat Mass Transf. 2013;66:235-43. https://doi. org/10.1016/j.ijheatmasstransfer.2013.07.019.

63. Ebrahimi A, Naranjani B, Milani S, Javan FD. Laminar convective heat transfer of shear-thinning liquids in rectangular channels with longitudinal vortex generators. Chem Eng Sci. 2017;173:264-74. https://doi.org/10.1016/j.ces.2017.07.044.

64. Ebrahimi A, Naranjani B. An investigation on thermo-hydraulic performance of a flat-plate channel with pyramidal protrusions. Appl Therm Eng. 2016;106:316-24. https://doi.org/10.1016/j. applthermaleng.2016.06.015.
65. Ebrahimi A, Roohi E. Numerical study of flow patterns and heat transfer in mini twisted oval tubes. Int J Mod Phys C. 2015;26(12):1550140. https://doi.org/10.1142/s01291831155014 05.

66. Sui Y, Lee P, Teo C. An experimental study of flow friction and heat transfer in wavy microchannels with rectangular cross section. Int J Therm Sci. 2011;50(12):2473-82. https://doi. org/10.1016/j.ijthermalsci.2011.06.017.

67. Berger SA, Talbot L, Yao LS. Flow in curved pipes. Annu Rev Fluid Mech. 1983;15(1):461-512. https://doi.org/10.1146/annur ev.fl.15.010183.002333.

68. Chandratilleke TT Nursubyakto. Numerical prediction of secondary flow and convective heat transfer in externally heated curved rectangular ducts. Int J Therm Sci. 2003;42(2:187-98. https://doi. org/10.1016/s1290-0729(02)00018-2.

69. Sajid MU, Ali HM, Sufyan A, Rashid D, Zahid SU, Rehman WU. Experimental investigation of $\mathrm{TiO}_{2}$-water nanofluid flow and heat transfer inside wavy mini-channel heat sinks. J Therm Anal Calorim. 2019;137(4):1279-94. https://doi.org/10.1007/s10973-01908043-9.

70. Xie G, Liu J, Liu Y, Sunden B, Zhang W. Comparative study of thermal performance of longitudinal and transversal-wavy microchannel heat sinks for electronic cooling. J Electron Packag. 2013; . https://doi.org/10.1115/1.4023530.

Publisher's Note Springer Nature remains neutral with regard to jurisdictional claims in published maps and institutional affiliations. 